\title{
BONDED-BOLTED COMBINATION REPAIR OF A COMPOSITE FUSELAGE SECTION
}

\author{
by \\ Romeo Isaacs \\ Bachelor of Engineering, Ryerson University (2014)
}

A project

Presented to Ryerson University

In partial fulfilment of the

Requirements for the degree of

Master of Engineering

In the Program of

Aerospace Engineering

Toronto, Ontario, Canada, 2017

CRomeo Isaacs 2017 


\section{AUTHOR'S DECLARATION}

I hereby declare that I am the sole author of this Master's research project. This is a true copy of the master's research project, including any required final revisions.

I authorize Ryerson University to lend this Master's research project to other institutions or individuals for the purpose of scholarly research.

I further authorize Ryerson University to reproduce this Master's research project by photocopying or by other means, in total or in part, at the request of other institutions or individuals for the purpose of scholarly research.

I understand that my Master's research project may be made electronically available to the public. 


\title{
BONDED-BOLTED COMBINATION REPAIR OF A COMPOSITE FUSELAGE SECTION
}

\author{
Romeo Isaacs \\ Master of Engineering, Aerospace Engineering, Ryerson University (2017)
}

\begin{abstract}
$\underline{\text { Abstract }}$
Composite repair is an area of great importance, especially in the aerospace industry, due to the fact that an increasing number of modern aircrafts are utilizing these materials in larger quantities and in numerous areas in an effort to take advantage of their superior mechanical and physical properties. However, as result of their higher costs when compared to metals, replacing damaged structures could be a costly endeavour which is why composite repair is an excellent avenue to explore. This project aims to examine the suitability of a bonded-bolted combination repair for a damaged fuselage section through simulation by means of a finite element analysis on a CAD model. Catia V5 was used to create the model and the analysis was done in Ansys workbench. The repair section was compared with an undamaged section and after the application of pressure loads, the results indicated that there was a $10 \%$ increase in the stress and structural deformation of the repaired model when compared to the undamaged model. In addition, the stress in the materials used in the model was below that of their endurance limit.
\end{abstract}




\section{Table of Contents}

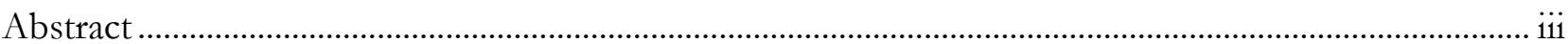

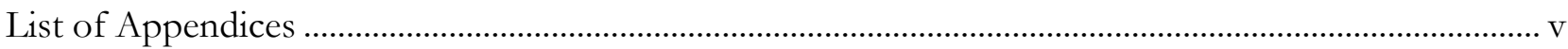

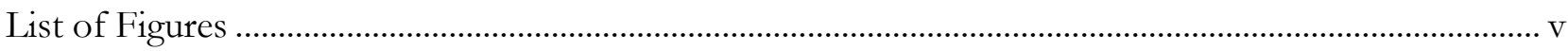

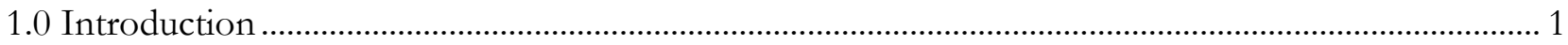

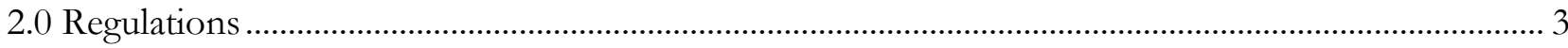

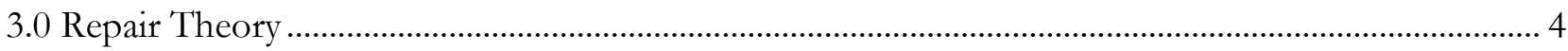

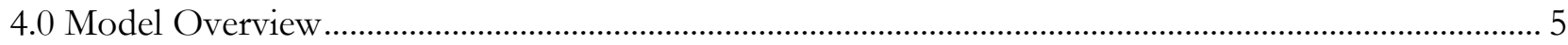

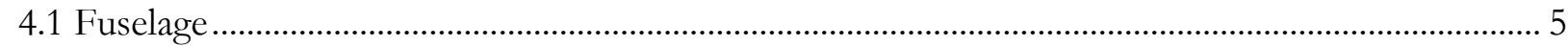

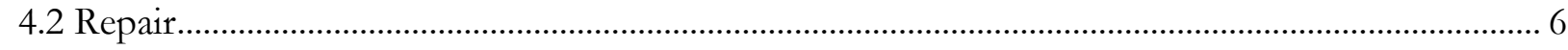

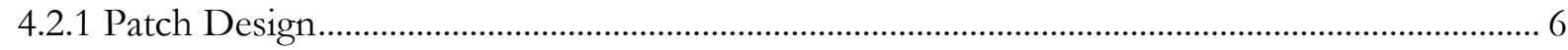

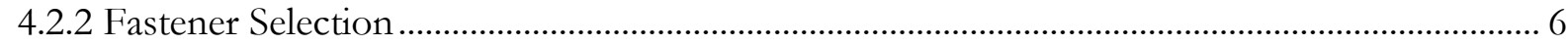

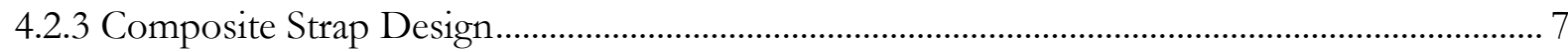

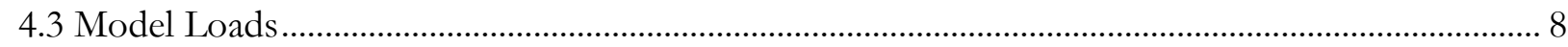

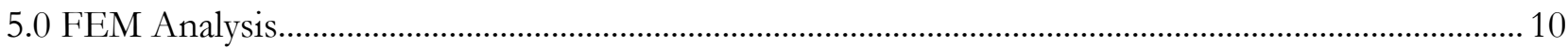

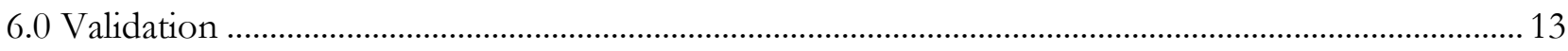

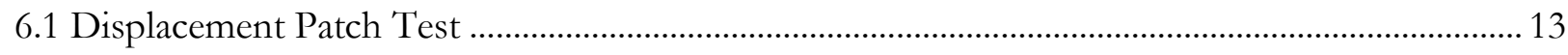

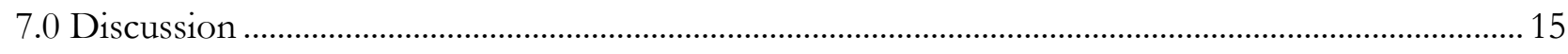

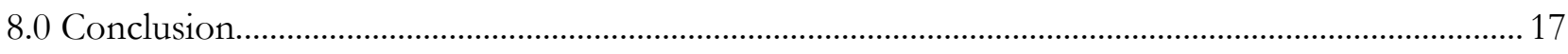

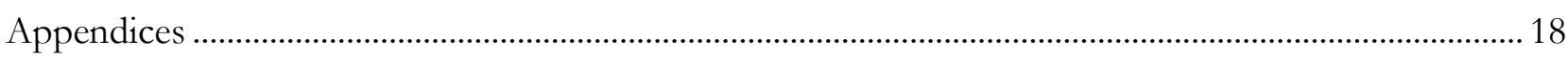

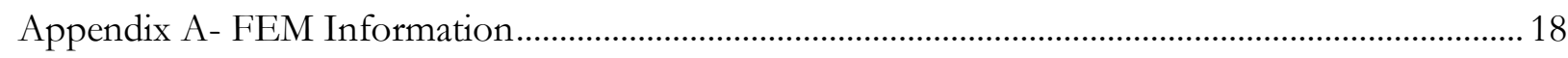

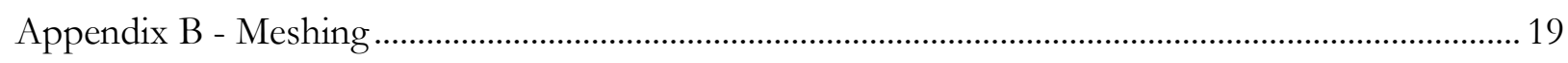

Appendix C - Part Geometry and Dimensions ................................................................................. 23

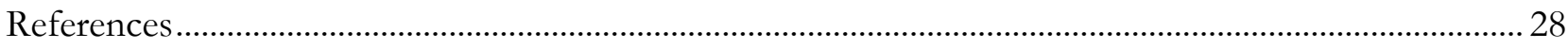




\section{List of Appendices}

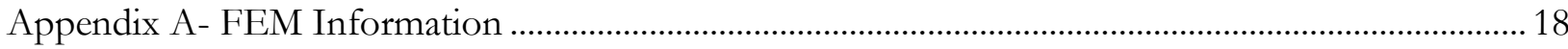

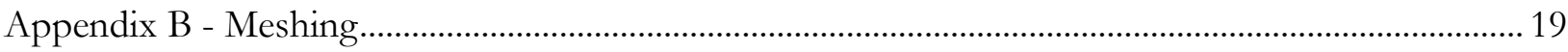

Appendix C - Part Geometry and Dimensions ................................................................................... 23

\section{$\underline{\text { List of Figures }}$}

Figure 1: Damaged section of aircraft [1] ………………………………………………………………….. 1

Figure 2: External skin damage [1] ................................................................................................. 1

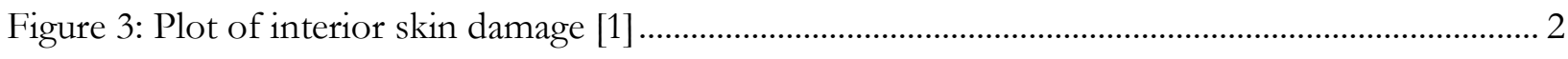

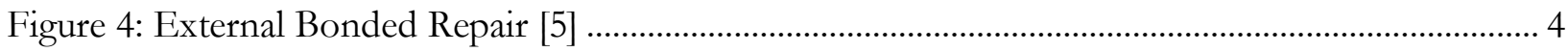

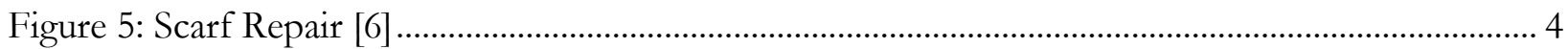

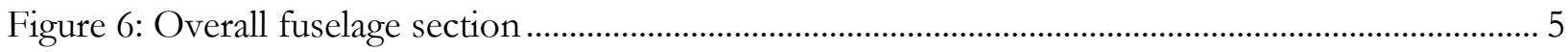

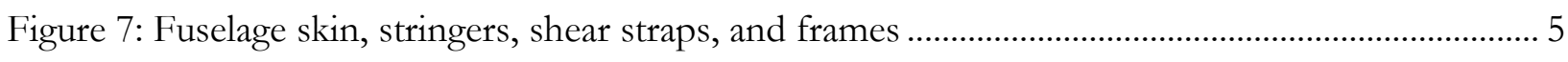

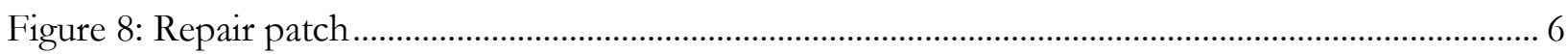

Figure 9: Visu-Lok 11 100 ${ }^{\circ}$ Flush Head Series [9] ..............................................................................

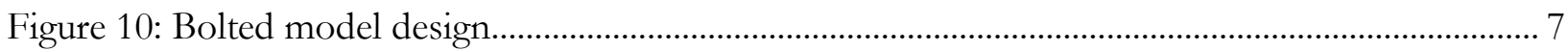

Figure 11: Composite straps a) flat b) molded straps......................................................................... 8

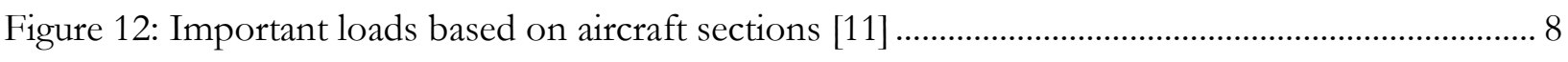

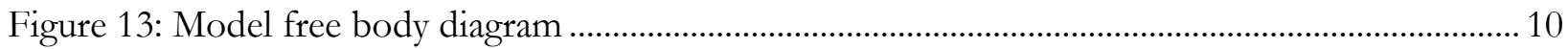

Figure 14: Deformation plot for repair section ………………………………………………………….. 10

Figure 15: Maximum principal stress plot for repair section ................................................................. 11

Figure 16: Deformation in an undamaged section ............................................................................. 11

Figure 17: Maximum principal stress plot for an undamaged section...................................................... 12

Figure 18: Central node on element for patch test ................................................................................. 13

Figure 19: Principal stress plots with centrally placed stress probes (a) repaired section (b) undamaged

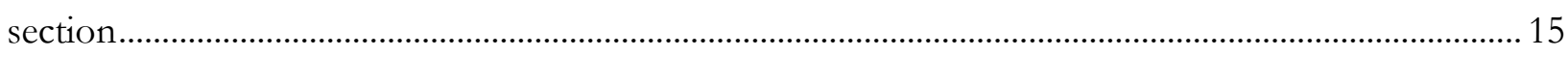

Figure 20: Deformation plots with probes at the bolted repair interface (a) repaired section (b)

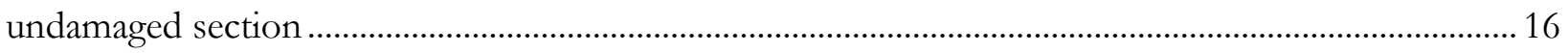

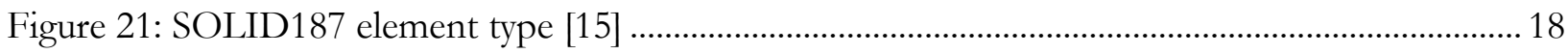




\subsection{Introduction}

In July 2013, a Boeing B787 aircraft suffered fire damage to its rear section caused by an Emergency Locator Transmitter (ELT) battery short circuit. The damaged area was 9.5 square meters and the result was that the fuselage skin, stringers, frames, and insulation blankets in this area had been damaged or destroyed. Figure 1 provides a representation of the insulations blankets and frames in the damaged section.

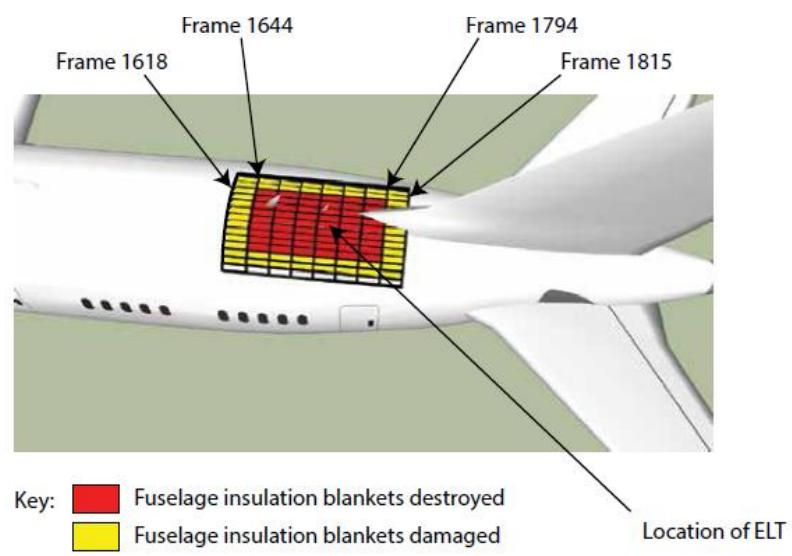

Figure 1: Damaged section of aircraft [1]

Areas adjacent to the ELT suffered severe structural damage in the form of significant resin loss and ply disbonding in the fuselage skin and frames [1]. The ELT, its mounting plate, and sections of the frames to which it was attached all suffered severe thermal damage [1]. Fire damage on the skin was interior between a number of stringers and exterior in the location of the ELT as shown in Figure 2.

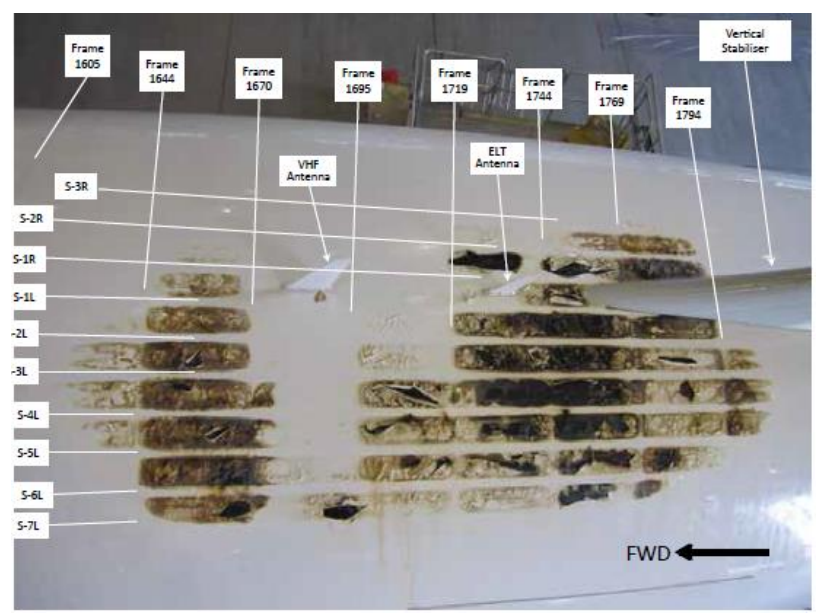

Figure 2: External skin damage [1] 
The frames and skin in the highly-damaged areas suffered an almost total resin loss. Following a visual test of the area, an ultrasonic test was performed. The ultrasonic survey identified areas of skin which had voids present or showed evidence of disbonding [1] as shown in Figure 3.

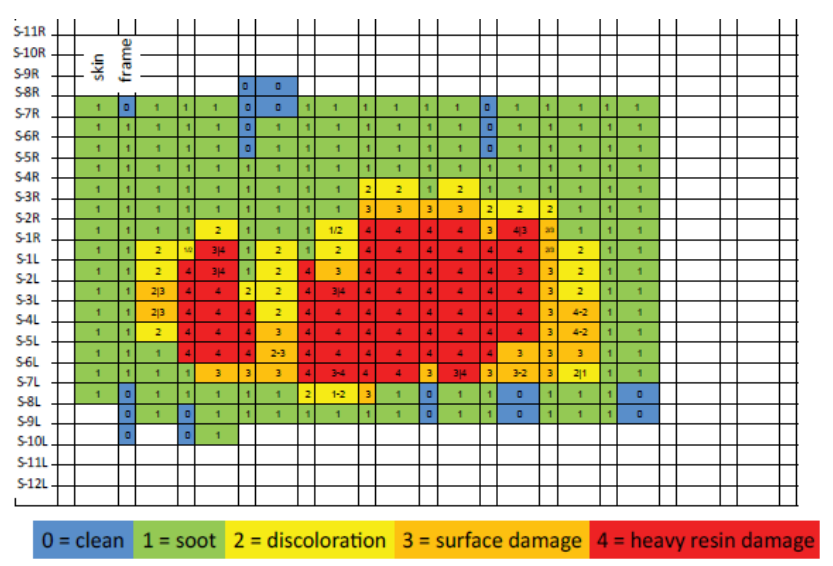

Figure 3: Plot of interior skin damage [1]

This project aims to examine the suitability of a bonded-bolted combination repair for a damaged fuselage section similar to the one on the B787. The original damaged section had an area of 0.37 square meters with the overall material removal being 0.66 square meters. The criteria for a suitable repair is such that it must withstand the ultimate load on the section before it can be deemed acceptable. 


\section{$\underline{2.0 \text { Regulations }}$}

Damage tolerance is a representation of a structure's ability to sustain design loads when damaged or carrying a defect and being able to perform its operating functions in spite of this. The philosophy originated from the safe life and fail safe approaches. The safe life approach limits the allowed operational life of a structure and thus ensures an adequate fatigue life while the fail-safe approach assumes failure but uses redundant systems which provide multiple load paths.

Civil aviation requirements for composites are addressed in Federal Aviation Regulations (FAR) 23.573, 25.571 (damage tolerance and fatigue evaluation), 27.571, 29.571 and Joint Airworthiness Requirements (JAR) 25.571 [2]. Current aeronautical requirements for composite structures with damage are [2]:

- Structures containing damage or defects that are not detectable during manufacturing inspections and service inspections must withstand Ultimate Load and not impair operation of the aircraft for its lifetime

- Structures containing damage that is detectable during maintenance inspections must withstand a once per lifetime load which is applied following repeated service loads occurring during an inspection interval

- All damage that lowers strength below Ultimate Load must be repaired when found

- Structure damage from an in-flight discrete source that is evident to the crew must withstand loads that are consistent with continued safe flight

- Any damage that is repaired must withstand Ultimate Load 


\subsection{Repair Theory}

A combination of bonding and bolting was proposed for the repair but the bonded repair type was the one that was mostly utilized. Bonded repairs can take the form of external patches, internal patches, or a full scarf or stepped repair [3], as shown in Figure 4 and Figure 5. External patches are usually stepped while internal patches can be stepped or scarfed. The scarf angle should be small enough, usually $2^{\circ}$ to $6^{\circ}$ [4], to facilitate smooth stress transfer between adherends and this also helps to prevent the adhesive from escaping.

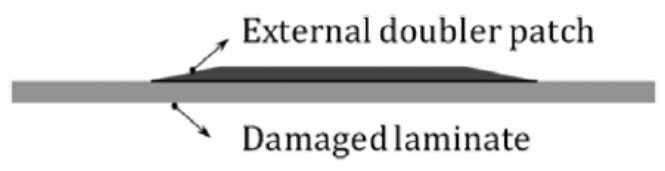

Figure 4: External Bonded Repair [5]

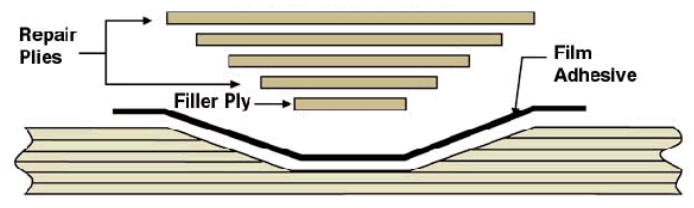

Figure 5: Scarf Repair [6]

Despite the benefits of scarf repairs, there are some drawbacks. First, in order to obtain a small taper angle, a large amount of material must be removed. Second, the replacement plies must be accurately laid up and placed in the repair joint. Third, if the replacement plies are not cured in an autoclave, there could be a reduction in strength. Fourth, the adhesive can run to the bottom of the joint and create a non-uniform bond line [2]. Due to these concerns, this type of repair is usually performed at a facility but can result in part strength that is as strong as the original.

The external patch repair is commonly used because of its simplicity. However, to maintain aerodynamic features, to minimize moment-induced failure modes, and to preserve weight, the flush scarf repair is preferred [3]. Applying internal or external patches requires the surface to be cleaned and lightly abraded before laying up the repair. For the flush repair, a hole is created as the damaged section is removed, and the patch is designed and fabricated to fit in the hole. The patch could be either pre-cured and secondarily bonded to the part or co-cured and adhesively bonded to the damaged area. It is thought that co-cured patches are generally stronger [3]. 


\subsection{Model Overview}

\subsection{Fuselage}

For the analysis, a representative model of a B787 fuselage section was created in Catia V5, see Figure 6 and Figure 7 using information found from research and other approximations. The design features a composite skin along with composite stringers, frames, and shear straps with titanium rivets and composite repair straps. The dimensions for each part can be found in Appendix C.

An arbitrary stacking sequence was used for the composite and the model was analyzed with unidirectional carbon/epoxy $395 \mathrm{GPa}$ prepreg from the Ansys library as a proof of concept. For the analysis, a 5.29 square meter portion of the fuselage containing the section to be repaired was cut out and used for analysis in an effort to reduce the computational resources required to carry out an analysis on the entire fuselage section.

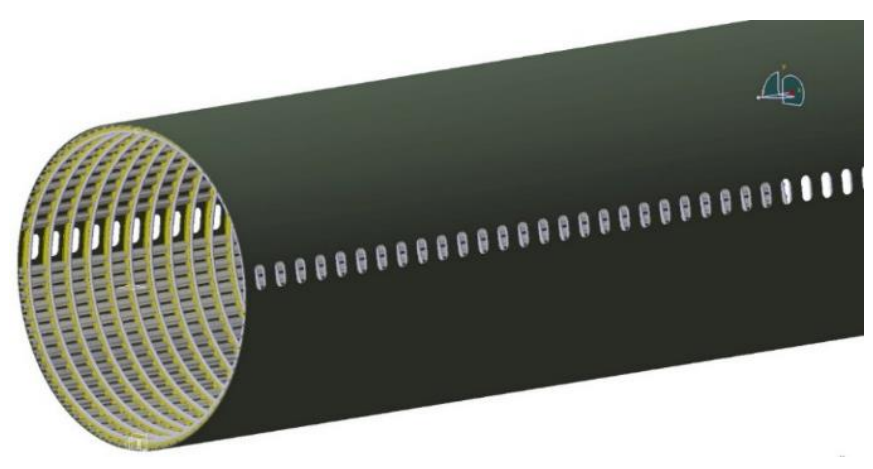

Figure 6: Overall fuselage section

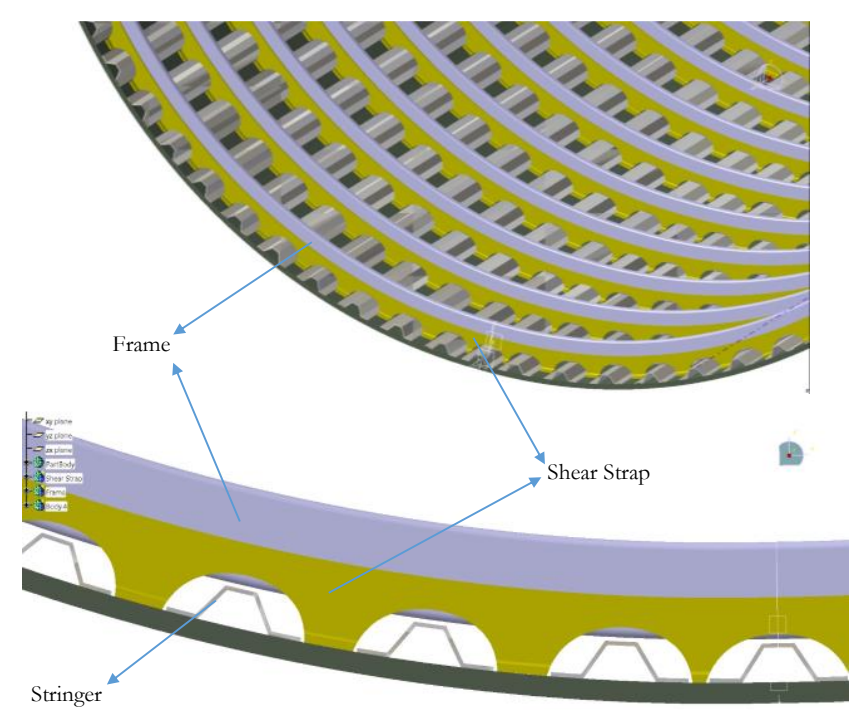

Figure 7: Fuselage skin, stringers, shear straps, and frames 


\subsection{Repair}

A scarf angle bonded repair which utilizes bolted titanium straps was designed and analyzed.

\subsubsection{Patch Design}

The $3 \mathrm{ft}$ outer diameter patch design with an $8^{\circ}$ flush scarf taper is as shown in Figure 8. Gama et al. (2004) noted that scarf angles between $2^{\circ}$ to $6^{\circ}$ were used with thin structures and researched using larger angles $\left(11.3^{\circ}\right.$ and $\left.18.4^{\circ}\right)$ for thicker structures to conserve the amount of material removed during the repair process. This is a disadvantage of the scarf repair as it can require the removal of an excess amount of good material from the repair area. Increasing the scarf angle, however, causes more load to be taken by the adhesive and can ultimately result in failure of the bond in the adhesive layer.

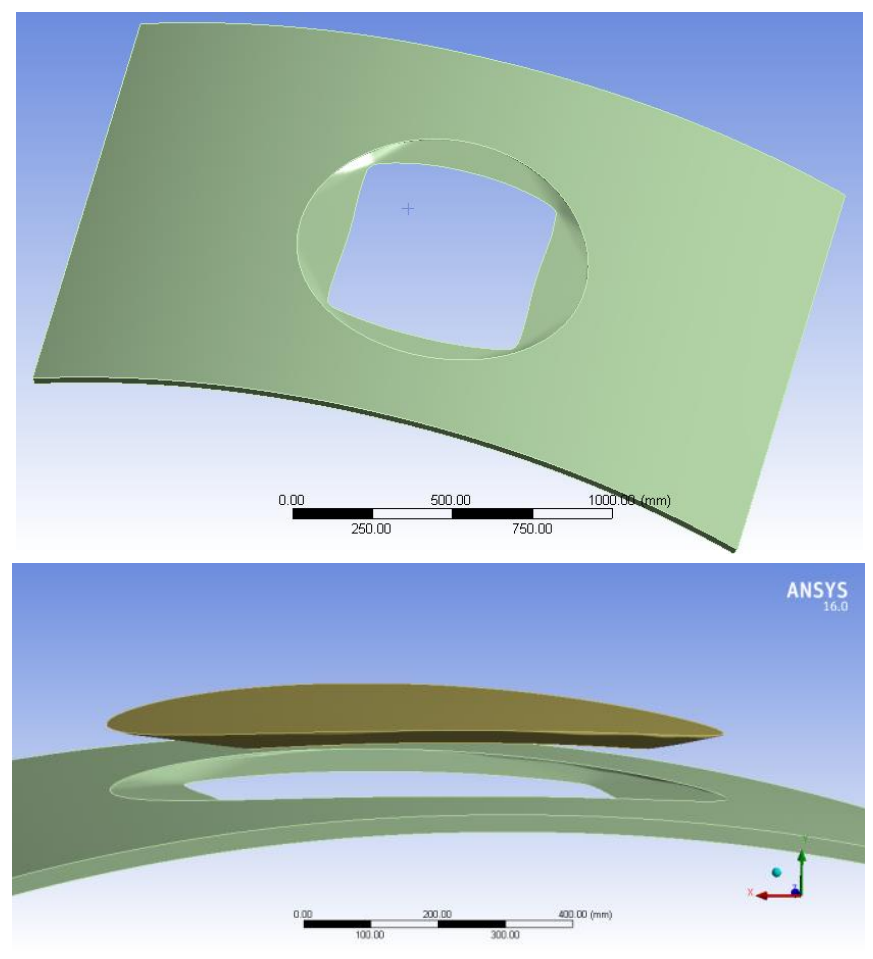

\subsubsection{Fastener Selection}

Fiaure 8: Renair natch

For bolted repair of carbon composite structures, the fasteners usually utilized are made from either titanium or corrosion resistant steel [7]. These fasteners should also have large heads which will help to prevent them from being pulled though the drilled holes in the composite. However, in this design, there are two titanium patches that serve to sandwich the composite structures and this makes fastener selection much easier. 
The fasteners selected for use in the bolted portion of the repair were the Visu-Lok fasteners similar to the schematic shown in Figure 9. This type of self-locking fastener consists of a preassembled nut, threaded bolt and sleeve [7]. The installation can be done by one person and can be accomplished by either hand or using power tools operating at standard air pressure levels [8].

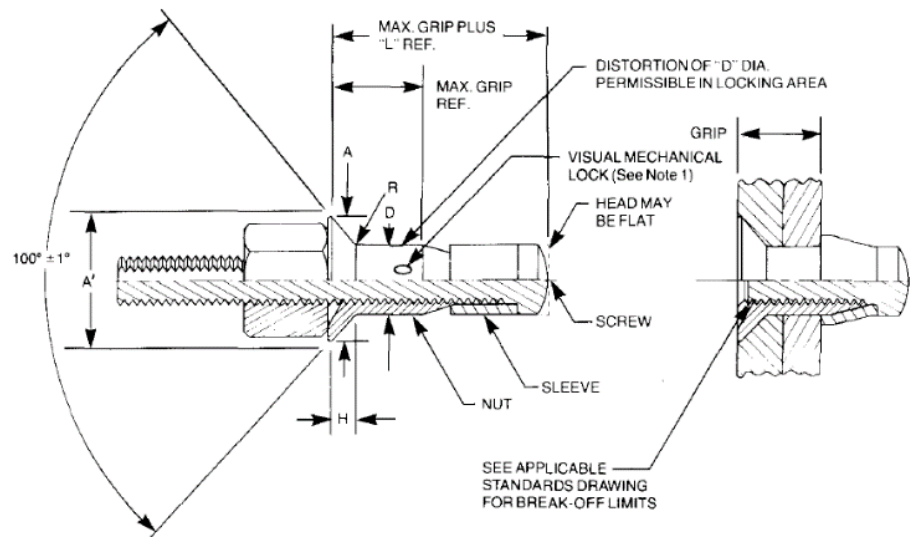

Figure 9: Visu-Lok ll 100 Flush Head Series [9]

The bolted model has three rows of eight fasteners as shown in Figure 10 all with off the shelf diameters D. The fasteners in the top two rows have a dimeter of 0.2 inches while the bottom row fasteners have a diameter of 0.25 inches.

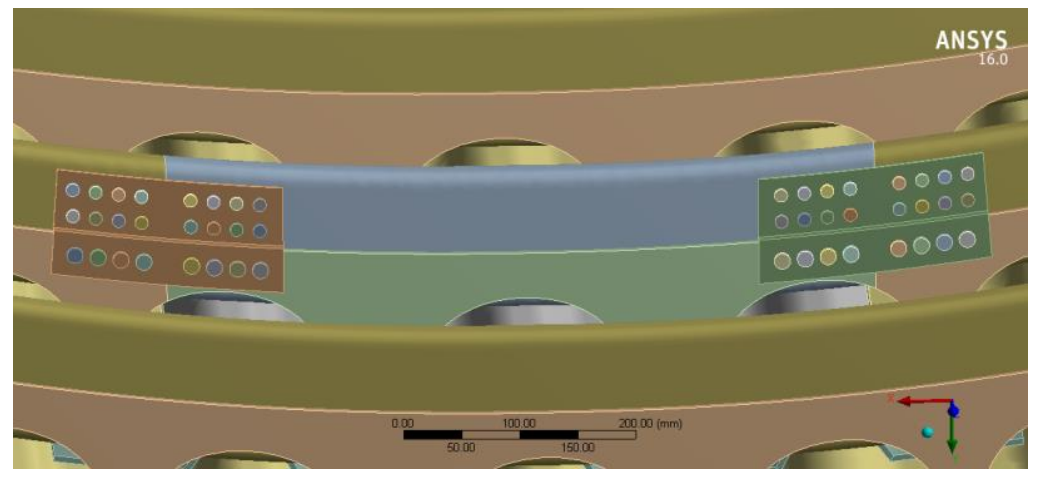

Figure 10: Bolted model design

\subsubsection{Composite Strap Design}

In an effort to reinforce the area where the patch and fuselage meet, two sets of composite straps attached to the inside of the fuselage were used in the design: flat, and molded as shown in Figure 11. The flat straps are between $85.7 \times 100 \mathrm{~mm}$ and $41.2 \times 100 \mathrm{~mm}$ plates while the molded straps are designed to fit over the stringers. In addition, both composite straps have the same stacking sequence as the stringers. 


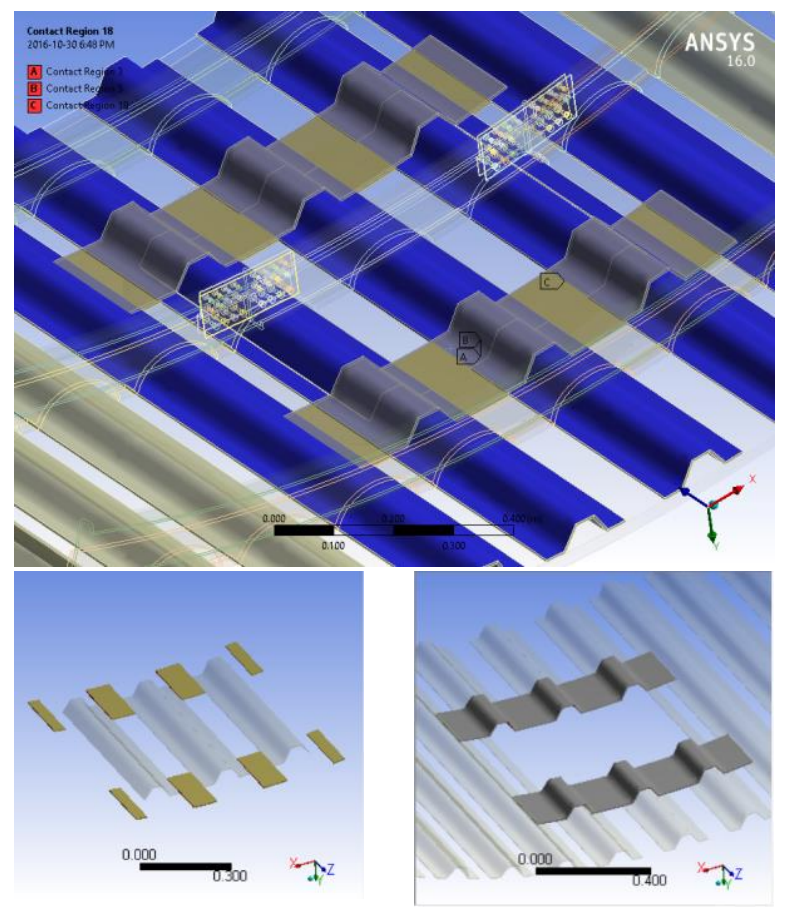

a)

b)

Figure 11: Composite straps a) flat b) molded straps

\subsection{Model Loads}

A number of different loads act on an aircraft during the course of a flight. These loads can be quasistatic such as flight loads (manoeuver and gust loads), ground handling loads (take off, landing, taxiing etc.) and local and internal loads (system pressure etc.); dynamic loads such as buffeting, vibrational loads, etc.; and fatigue loads [10].

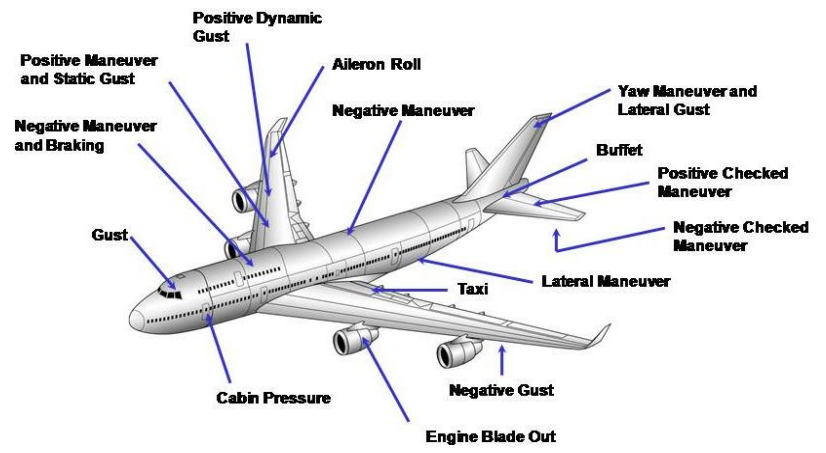

Figure 12: Important loads based on aircraft sections [11]

For the purposes of the analysis, static loads related to the aircraft flying at maximum altitude with maximum take-off weight were considered. Dynamic loads, such as buffeting and other vibrational 
loads, along with fatigue loads were not considered to simplify the analysis and obtain more reliable results. Figure 12 gives an indication of how various in-flight conditions can affect certain sections of the aircraft. Due to the location of the damage, the most important loads will be those due to the pressure differential between the cabin and the outside atmosphere and the compressive loads attributed to the bending of the fuselage during flight, although the latter will not be included in this analysis. Table 1 shows the variables which were used to carry out the finite element analysis.

Table 1: Model variables

\begin{tabular}{|l|c|}
\hline Cabin pressure $(6000 \mathrm{ft})\left(\mathrm{N} / \mathrm{m}^{2}\right)$ & $81,204.8$ \\
\hline Pressure at maximum altitude $(43000 \mathrm{ft})\left(\mathrm{N} / \mathrm{m}^{2}\right)$ & $16,304.6$ \\
\hline Load factor [12] & 3.8 \\
\hline Safety factor [13] & 1.5 \\
\hline Applied pressure $(\mathrm{MPa})$ & 0.37 \\
\hline
\end{tabular}




\section{$\underline{5.0}$ FEM Analysis}

The composite analysis was carried out in the Ansys workbench using the composite pre-processing and mechanical model component systems and the static structural analysis systems. The model assumed for the analysis had a total of 3,317,540 solid elements and other model information can be found in Appendix A. A free body diagram of the model with fixed supports and applied load P is as

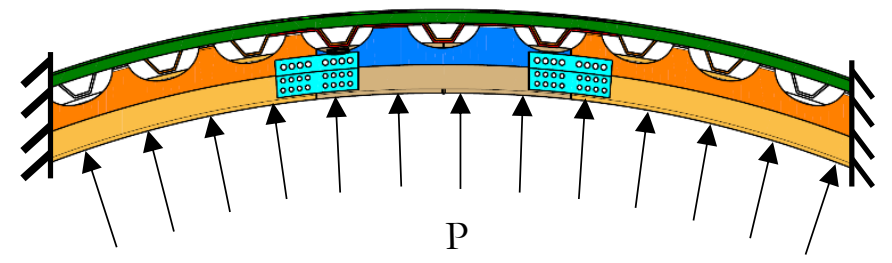

shown in

Figure 14.

Figure 14: Model free body diagram

The adhesive layer was represented by the bonded contact type definition in Ansys and the results of applying the load on the repair model are shown in the form of a displacement, and maximum principal stress plots as shown in Figure 13 and Figure 15 respectively.
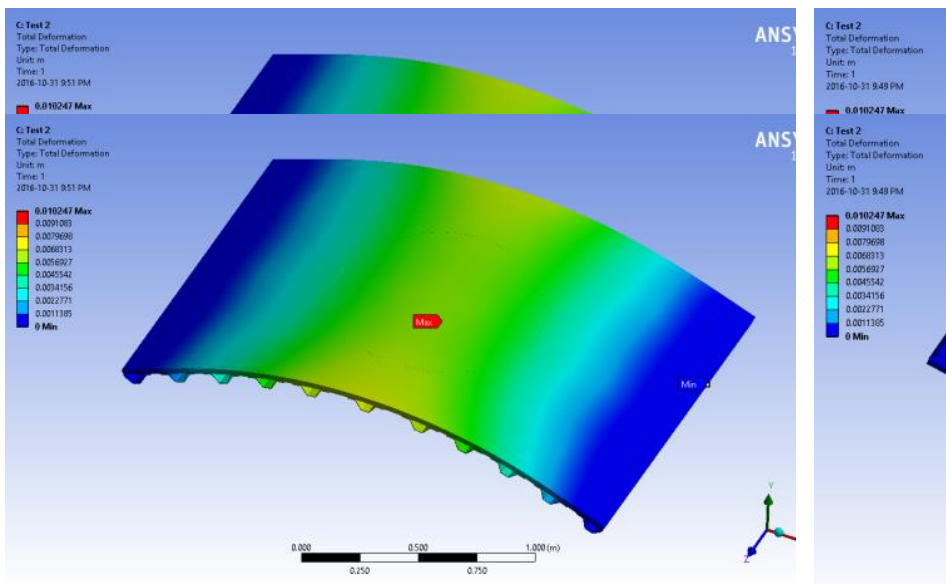

Fiqure 13: Deformation plot for repair section

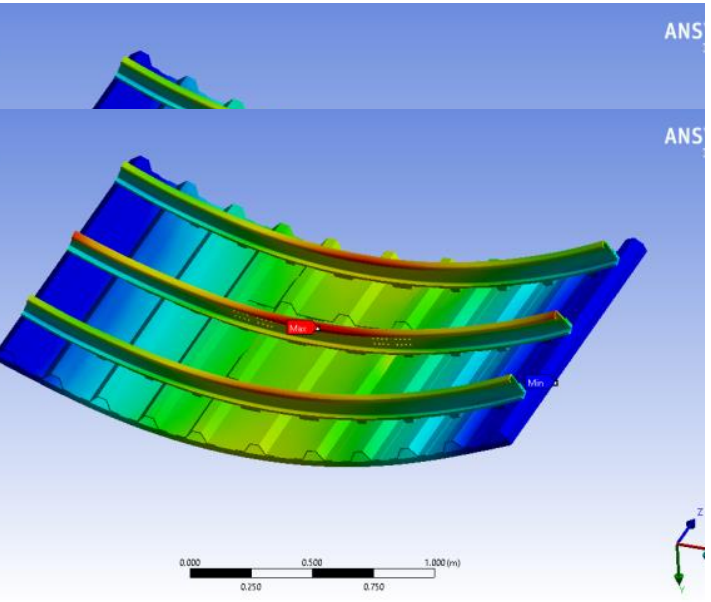

$\digamma$ 


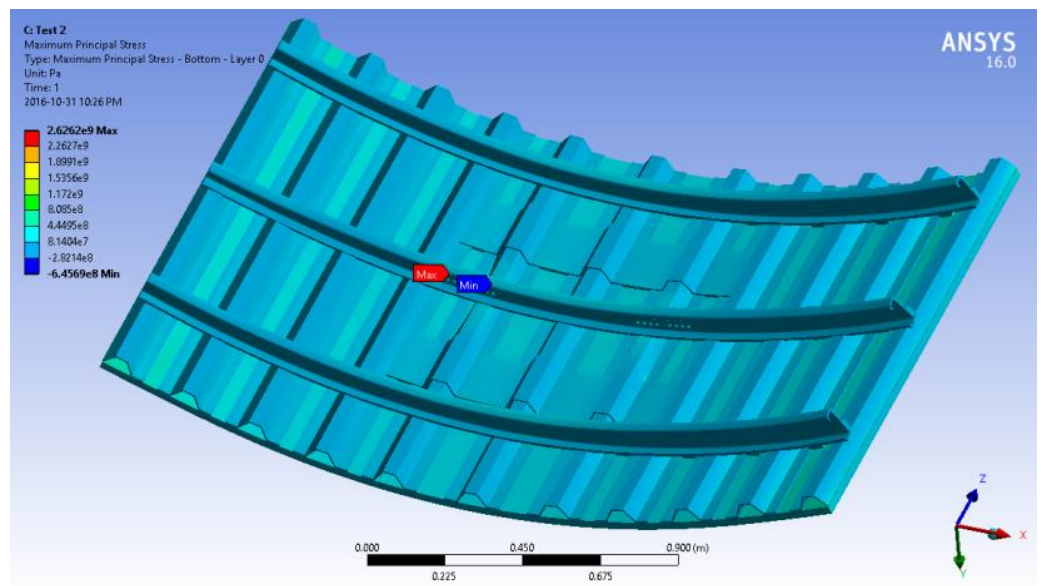

Figure 15: Maximum principal stress plot for repair section

From Figure 13, it can be seen that the greatest deformation occurs in and around the area where the damaged section has been removed. This was expected because the removal of the damaged section introduced a discontinuity to the structure which would affect the load and stress distribution. Using the principal stress distribution, shown in Figure 15, it could be inferred that the use of the bonded repair did not introduce a huge stress discontinuity in the damaged region. Figure 16 and Figure 17 show the deformation and stress plots for an undamaged fuselage section. Comparing the deformation plots for the repaired and undamaged section, it can be seen that the maximum deformation of the undamaged section is greater than that of the repaired section, almost 1.8 times more. However, comparing the deformation of the undamaged and repaired skin of the two models, it was found that these were very similar.
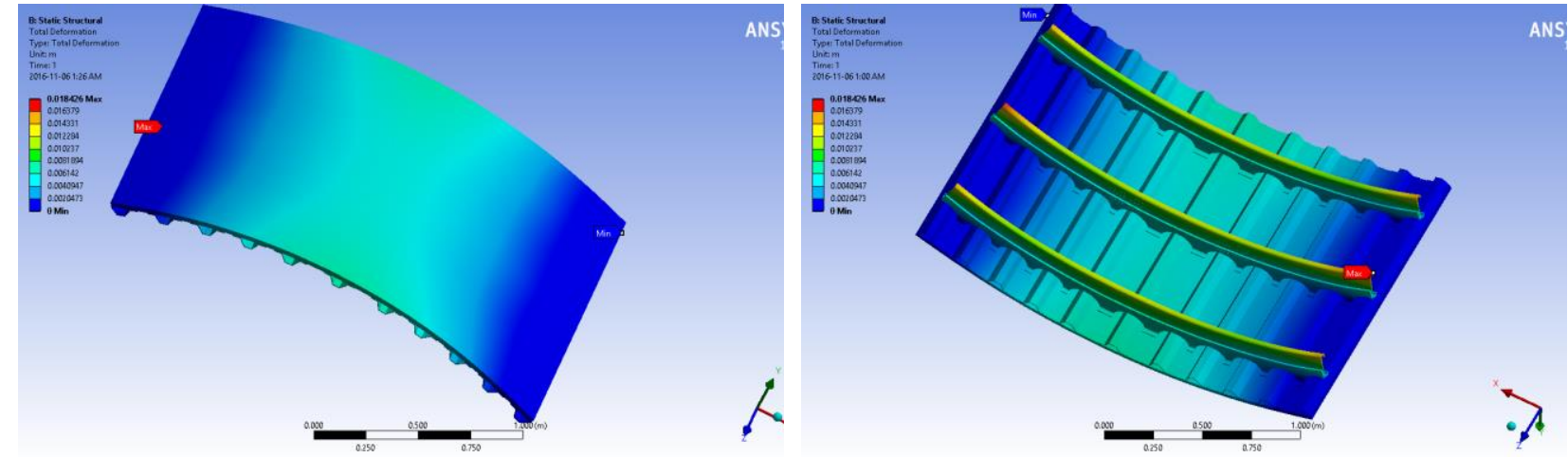

Fiaure 16: Deformation in an undamaaed section 


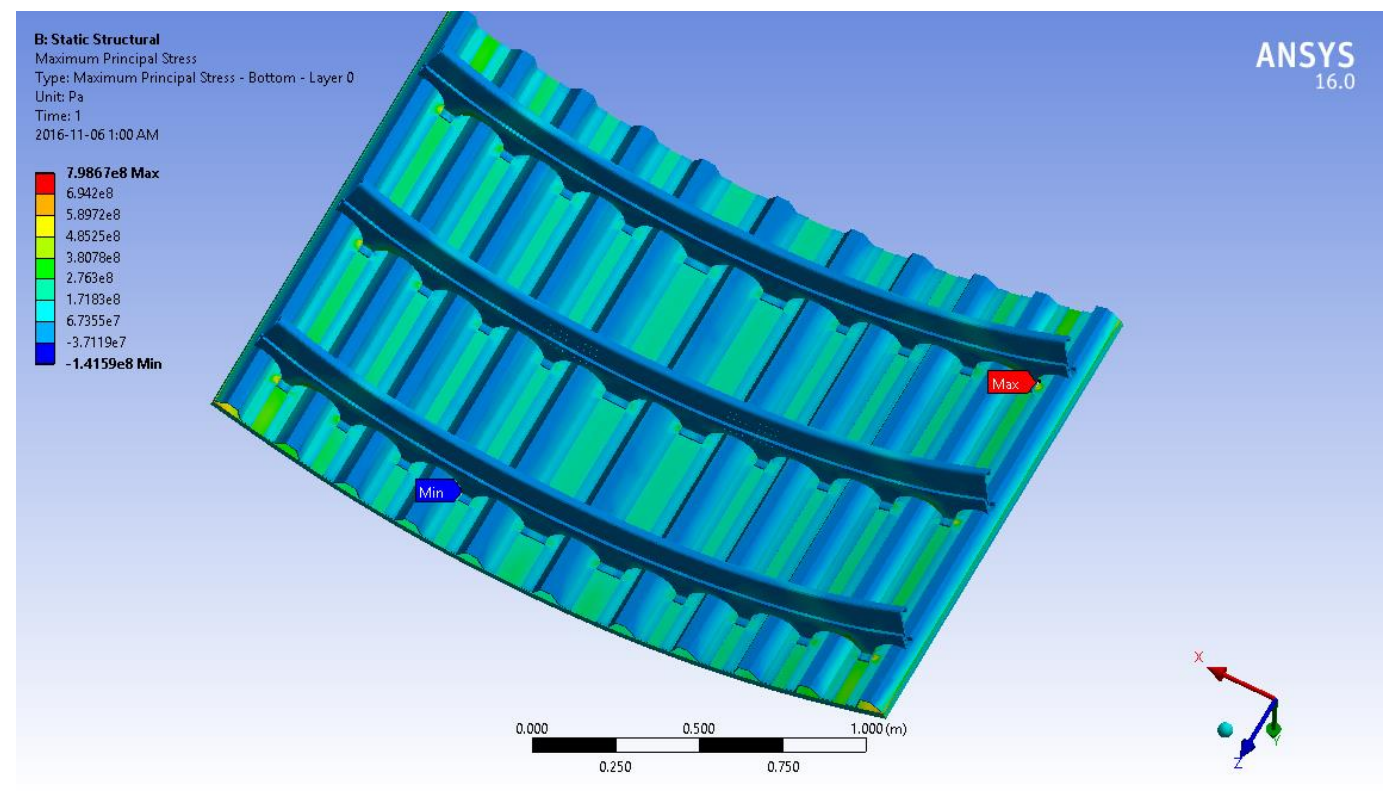

Figure 17: Maximum principal stress plot for an undamaged section

Comparing the principal stress plots for the damaged and undamaged sections, it can be seen that the maximum stress in the undamaged section is over three times as much as that in the repaired section. The results indicate that the overall stiffness of the model increased with the application of the bonded bolted combination repair. 


\section{$\underline{6.0 \text { Validation }}$}

In order to validate the results, a patch test was used. This was so because results directly related to the type of analysis performed along with the composite layup, loading conditions, and assumptions made were not readily available. However, if an element passes a patch test, convergence is guaranteed [14]. The patch test is based on the requirements that an element must accommodate rigid body modes as well as constant states of strain. It verifies that an arbitrary patch of assembled elements reproduces the behaviour of an elastic body when subjected to displacements and forces consistent with constant stress and strain. The type of patch test performed was the displacement patch test and the element on which the test was performed was the skin which was meshed with triangular (tetrahedral) and quadrilateral mesh elements.

\subsection{Displacement Patch Test}

This test can be used to determine if the elements can represent rigid body motion and a constant state of strain [14] by applying boundary displacements. The process involved applying an arbitrary displacement of $\mathrm{x}=10 \mathrm{~mm}$ to the nodes on the boundary of the element while keeping the displacements in the other directions ( $\mathrm{x}$ and $\mathrm{z}$ ), and the forces as zero. To pass the test, the computed $\mathrm{x}$ - and $\mathrm{z}$ - displacements along with the strains at the node located as shown in Figure 18 had to be zero. Sample results from the test are shown in Figure 2 and it can be seen that the element passed the displacement test

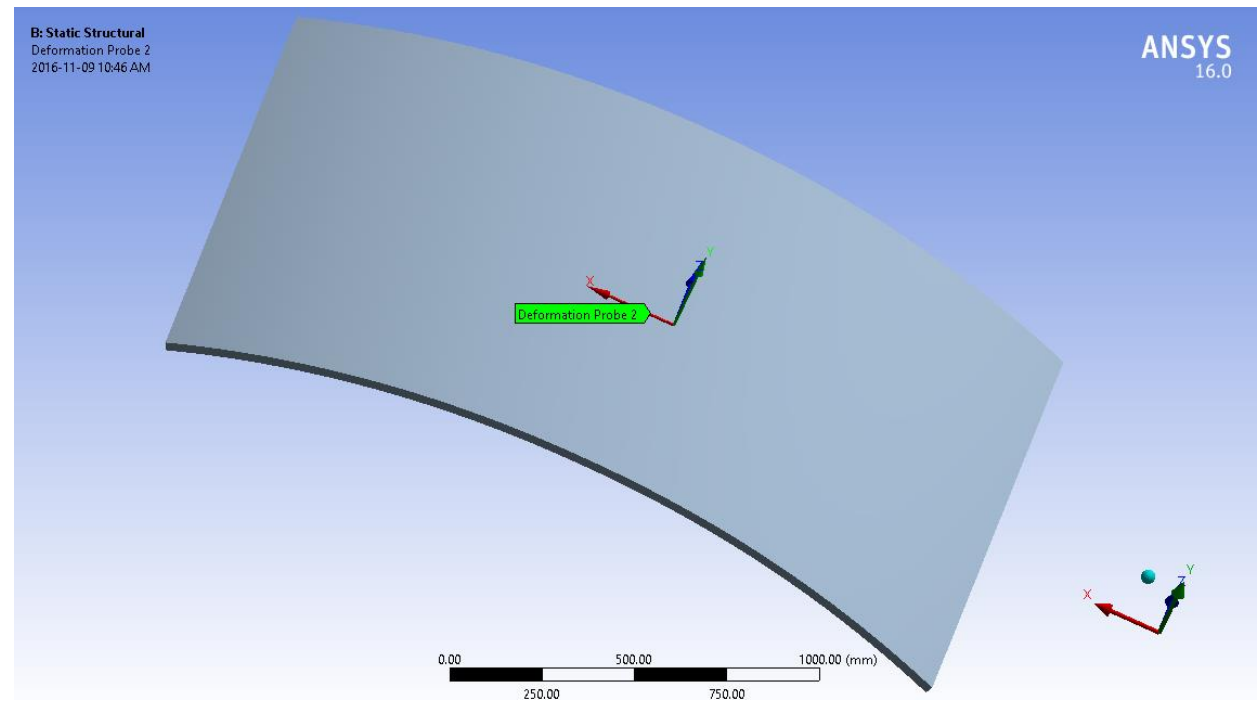

Figure 18: Central node on element for patch test 
Table 2: Sample results from displacement patch test

\begin{tabular}{|c|c|c|c|c|c|c|c|c|c|}
\hline \multirow{2}{*}{ Mesh type } & \multirow{2}{*}{$\begin{array}{c}\text { Element } \\
\text { size } \\
(\mathrm{mm})\end{array}$} & \multirow{2}{*}{$\begin{array}{c}\text { Number } \\
\text { of } \\
\text { elements }\end{array}$} & \multirow{2}{*}{$\begin{array}{l}\text { Number } \\
\text { of nodes }\end{array}$} & \multicolumn{3}{|c|}{ Displacement (mm) } & \multicolumn{3}{|c|}{ Strain $(\mathrm{mm} / \mathrm{mm})$} \\
\hline & & & & $\mathbf{x}$ & $\mathbf{y}$ & $\mathbf{z}$ & $\mathbf{x}$ & $\mathbf{y}$ & $\mathbf{z}$ \\
\hline Quadrilateral & \multirow{3}{*}{40} & & & & & & & & \\
\hline Dominated & & 90480 & 96760 & 10 & $7.85 e-09$ & $1.03 \mathrm{e}-10$ & $7.7 \mathrm{e}-11$ & $1.7 \mathrm{e}-10$ & $5.6 e-11$ \\
\hline Triangles & & 190960 & 101885 & 10 & $4.72 \mathrm{e}-09$ & $7.56 \mathrm{e}-11$ & $1.1 \mathrm{e}-10$ & $2.1 \mathrm{e}-10$ & $7.4 \mathrm{e}-11$ \\
\hline
\end{tabular}

Using the results from the displacement patch test, it was determined that combining the triangular and quadrilateral mesh elements allowed for the use of less elements in the analysis which in turn would reduce computational time without sacrificing the accuracy of the results and as such this method was chosen as the primary method of meshing. 


\subsection{Discussion}

A closer look at the stress and displacement probes placed centrally on the fuselage skin gives a clearer picture of the results from the analysis. Figure 19 shows the principal stress plot comparisons. The deformation and principal stress in the damaged region increased by approximately $10 \%$ when compared to the undamaged region. One of the advantages of the bonded repair is that the stacking sequences and materials of the repair can be chosen to match that of the parent structure materials. This is intended to reduce the discontinuity in properties between the parent structure materials and repair patch and could be one of the reasons for this small change in the properties. It may also be possible to reduce further the difference in deformation and stress by reducing the scarf angle of the repair but this would also require the removal of more undamaged material from the structure. One assumption made during the model definition was that the contact between the patch and the parent structure was bonded. This meant that the contacting surfaces were assumed to be glued together in the program during the analysis. It must be noted, however, that the stacking sequence of composite adherends may influence the scarf joint strength and stress resulting in non-uniform stress and shear distribution. The use of a bonded contact type does not account for this variation in the strength and stress and therefore represents a simplification of the joint.

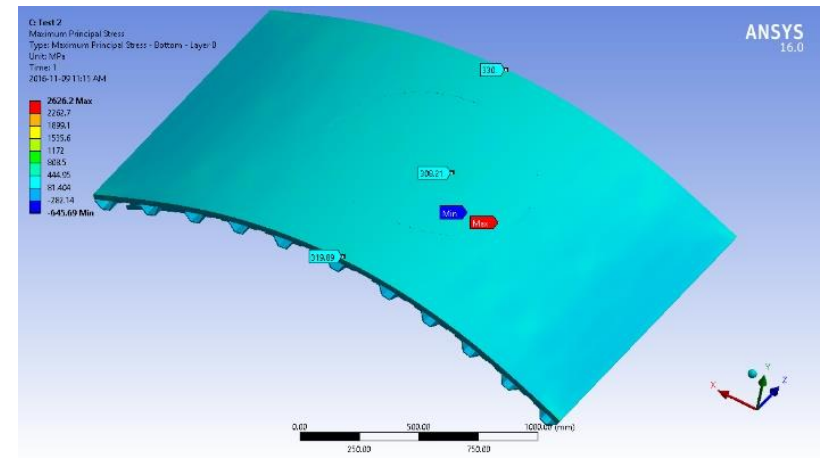

a)

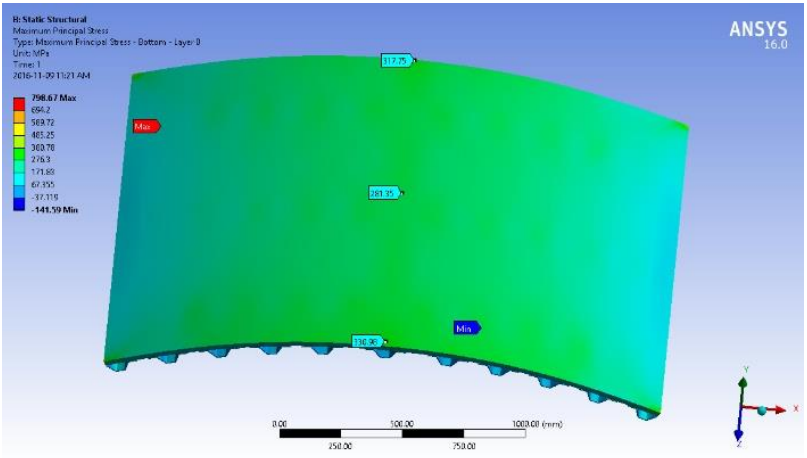

b)

Figure 19: Principal stress plots with centrally placed stress probes (a) repaired section (b) undamaged section

A look at the inside of the fuselage at the interface between the bolted titanium straps, the repair frame, and the parent structure indicated that there was also a 16\% reduction in the deformation in the repair and a 2.5 times increase in the maximum principal stress as compared to the undamaged structure. Unlike with the bonded portion of the repair, there is a greater discrepancy between the material properties in the bolted repair region due to presence of both metal and composite materials. This could mean that the bolted repair region is less ductile than that of the bonded region which would explain the reduction in the deformation and the corresponding increase in the stress. In addition, the presence 
of drilled holes would also create concentrations of stress in the area which could also explain the discrepancy.

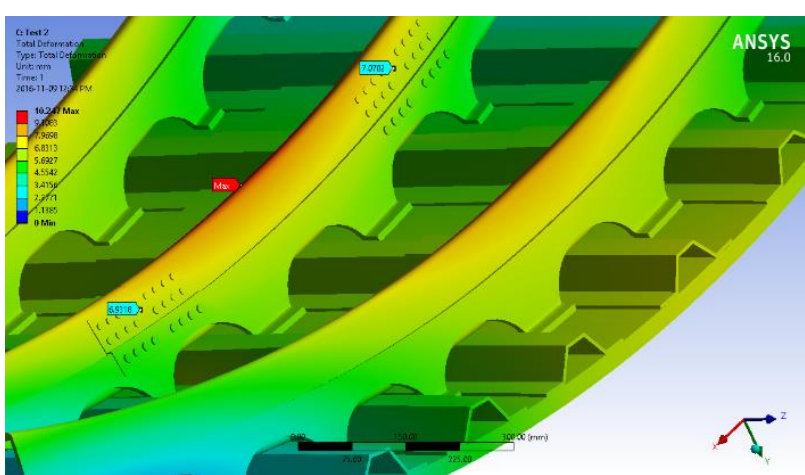

a)

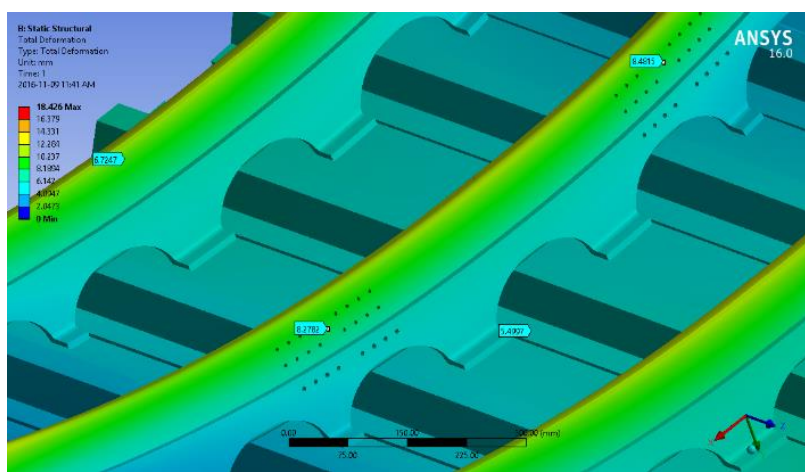

b)

Figure 20: Deformation plots with probes at the bolted repair interface (a) repaired section (b) undamaged section

The stress in the repaired structure is below the allowable stress for the carbon epoxy composite and titanium materials which would be used to indicate that the design did not fail. However, since only one type of loading was tested, the model would also have to be subjected to the compression and twisting loads experienced during flight along with fatigue loads to simulate years of use in order to get a more comprehensive picture of the integrity of the repair. 


\section{$\underline{8.0 \text { Conclusion }}$}

The goal of this project was to propose and apply a repair methodology for a damage to a fuselage which penetrated the skin and reached the underlying stringers, frames, and shear straps. The combination of a scarf type bonded repair along with a bolted repair was used because it allowed for the preservation of the aerodynamic integrity of the structure on the outside of the fuselage as well as the production of a repair whose strength could be closer to that of the undamaged structure. The bolted repair utilized on the inside of the structure allowed for the easy joining of the frames and shear straps without introducing undue stress, strain, and unnecessary weight to the damaged region. The stress and deformation in the bonded repair increased by 10\% when compared to the undamaged model but a further reduction could be realized by decreasing the scarf angle of the repair. The only drawback of this is that it would require the removal of more undamaged material from fuselage. In order to obtain a clearer picture of the suitability of this design, fatigue, bending, and torsional loads along with the modelling of the adhesive layer would have to be incorporated into the analysis. 


\section{$\underline{\text { Appendices }}$}

\section{Appendix A- FEM Information}

\begin{tabular}{|l|c|}
\hline Number of total nodes & 2854678 \\
\hline Number of contact elements & 747798 \\
\hline Number of bearing elements & 2569742 \\
\hline Number of total elements & 3317540 \\
\hline CP Time (sec) & 9590.766 \\
\hline Element type & SOLID187 \\
\hline Contact name & CONTA174 \\
\hline
\end{tabular}

Element Type - SOLID187 (quadratic order)

The SOLID187 element type (see Figure 21) is a higher order 3D, 10-node element [15]. This element type has a quadratic displacement behaviour and features 3 degrees of freedom at each node. In addition, it also has plasticity, hyper-elasticity, creep, stress stiffening, large deflection, large strain, and mixed formulation capabilities for simulating deformations of nearly incompressible elastoplastic materials and fully incompressible materials [15].

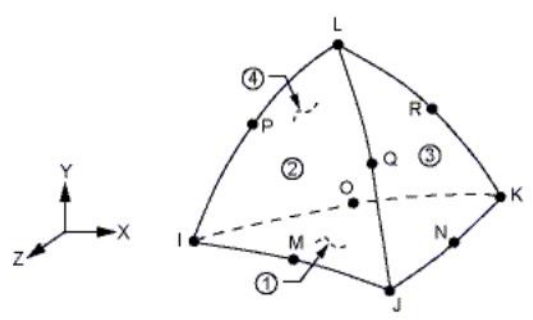

Figure 21: SOLID187 element type [15]

\section{Contact Type - CONTA174}

CONTA174 is used to represent contact and sliding between 3D target surfaces and a deformable surface [16]. This element type also has three degrees of freedom at each node and has the same geometric characteristics as the solid element face between which it is connected [16]. 
Appendix B - Meshing
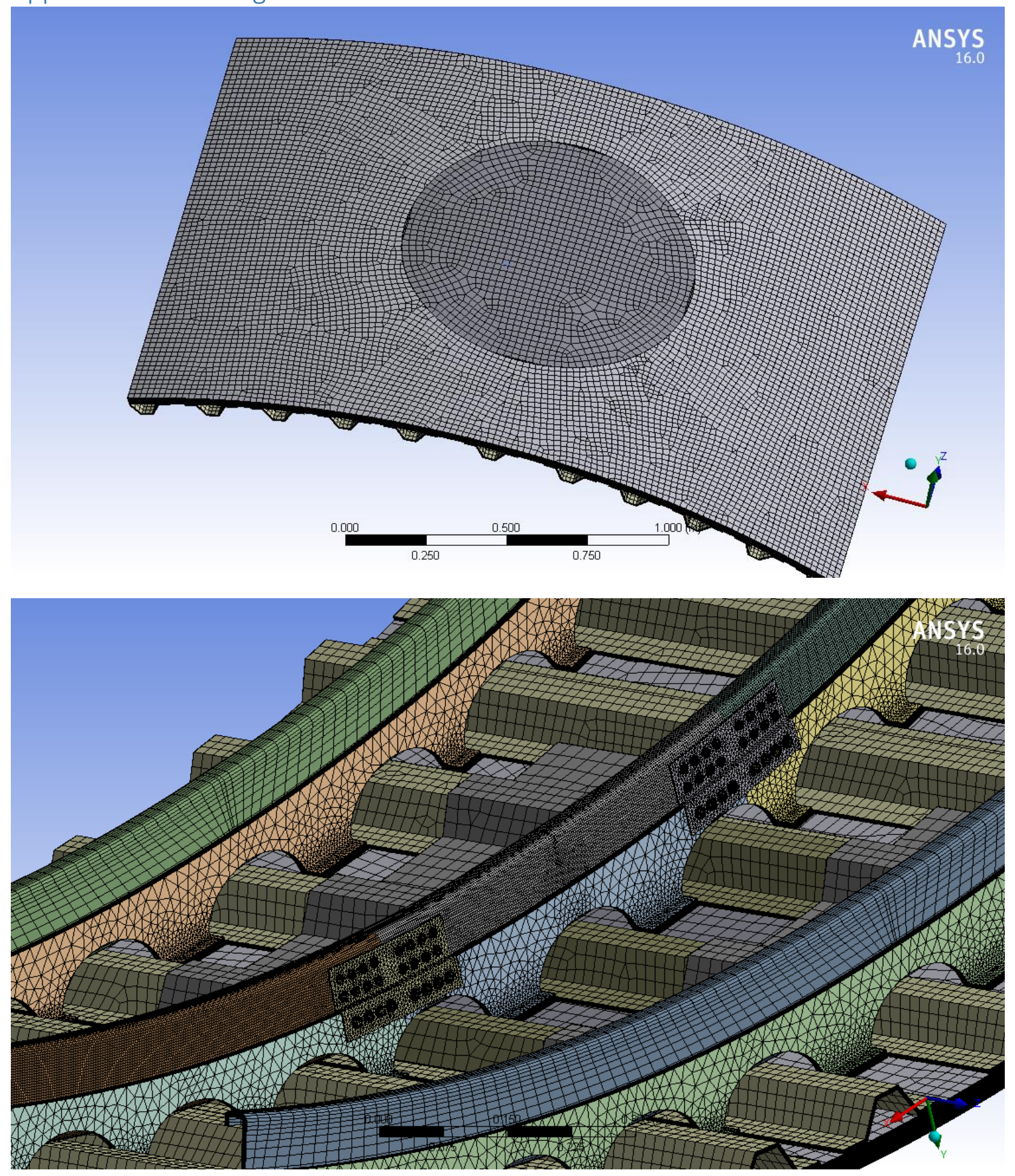

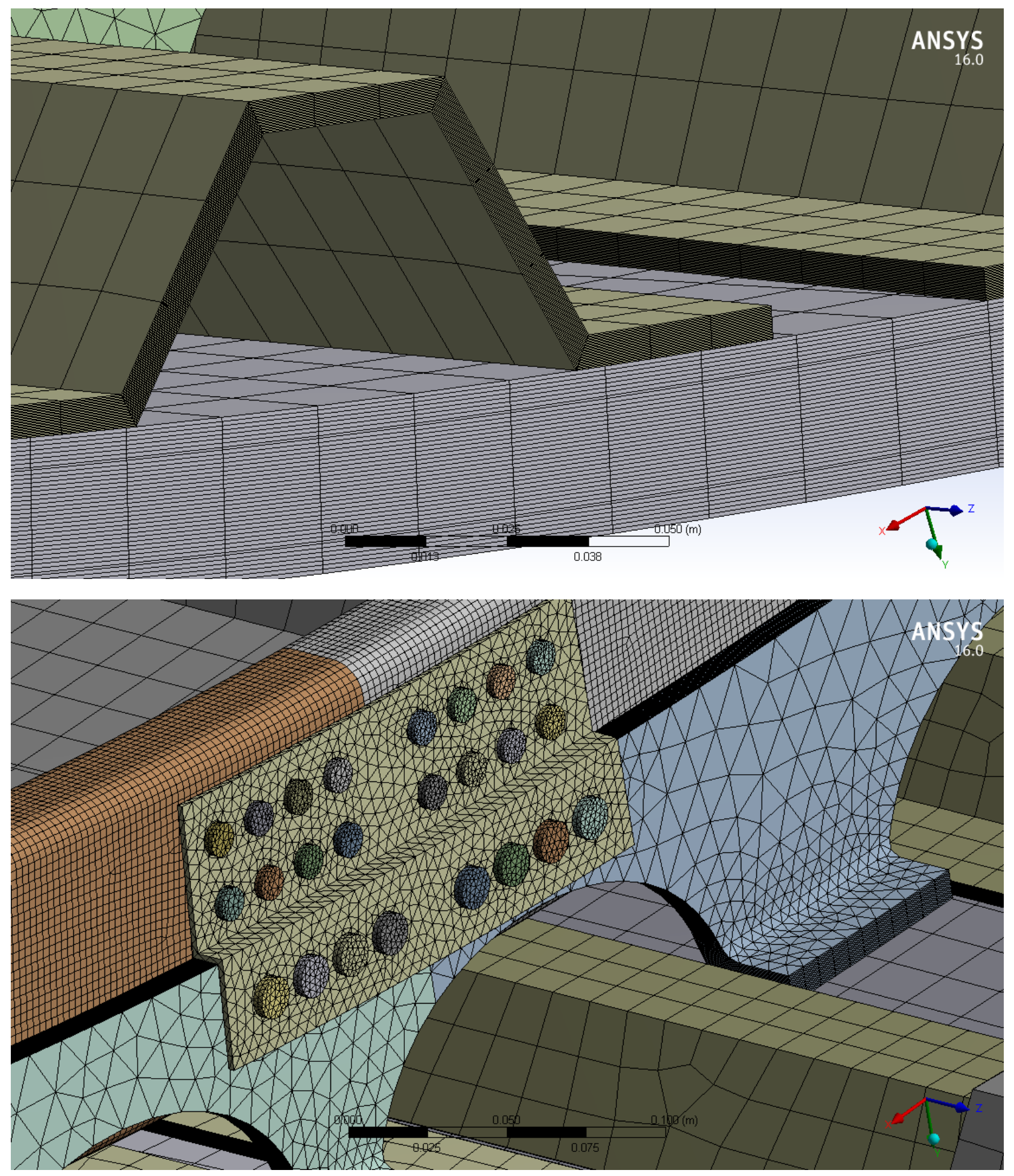

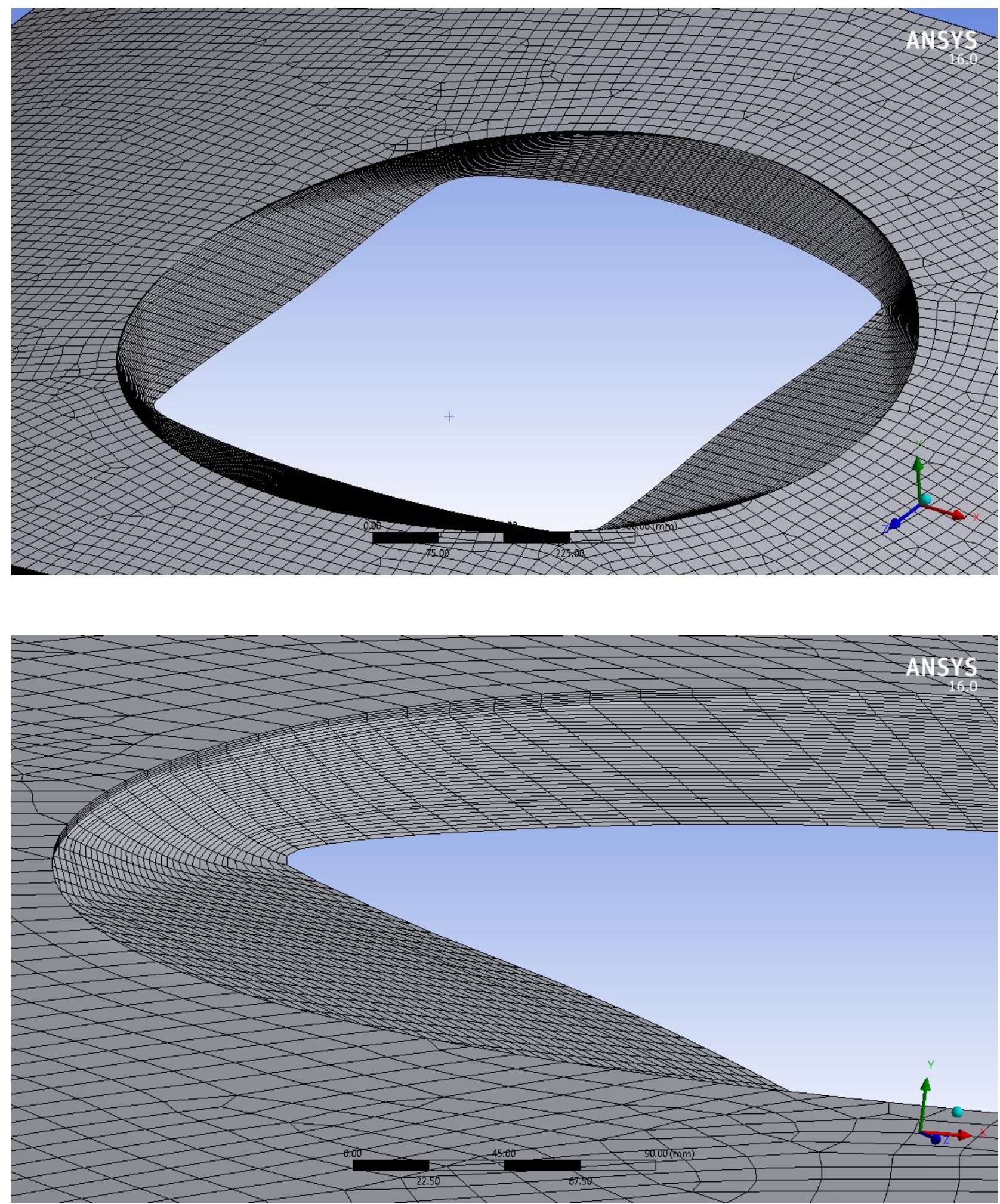


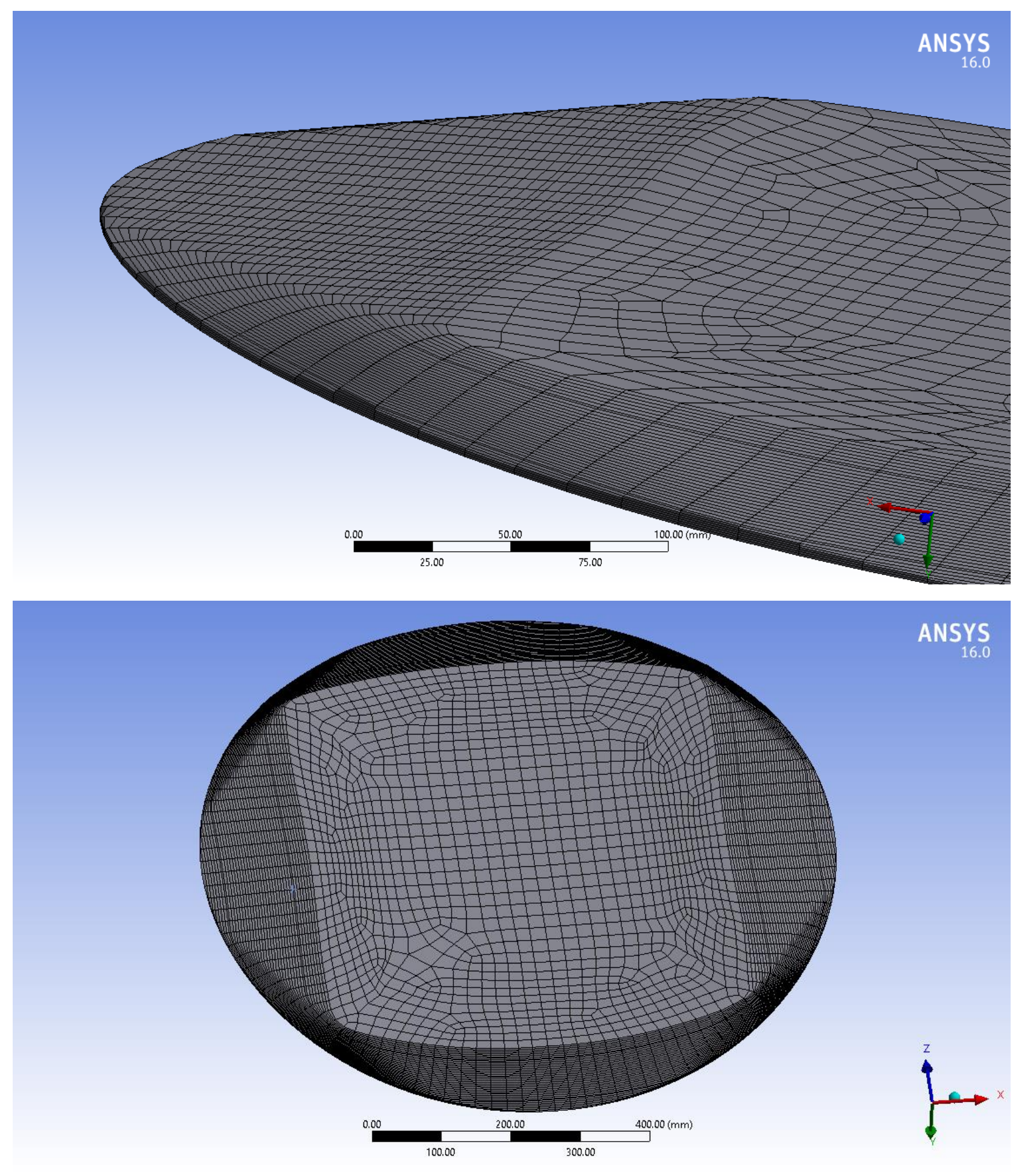


Appendix C - Part Geometry and Dimensions

(all dimensions in $\mathrm{mm}$ )

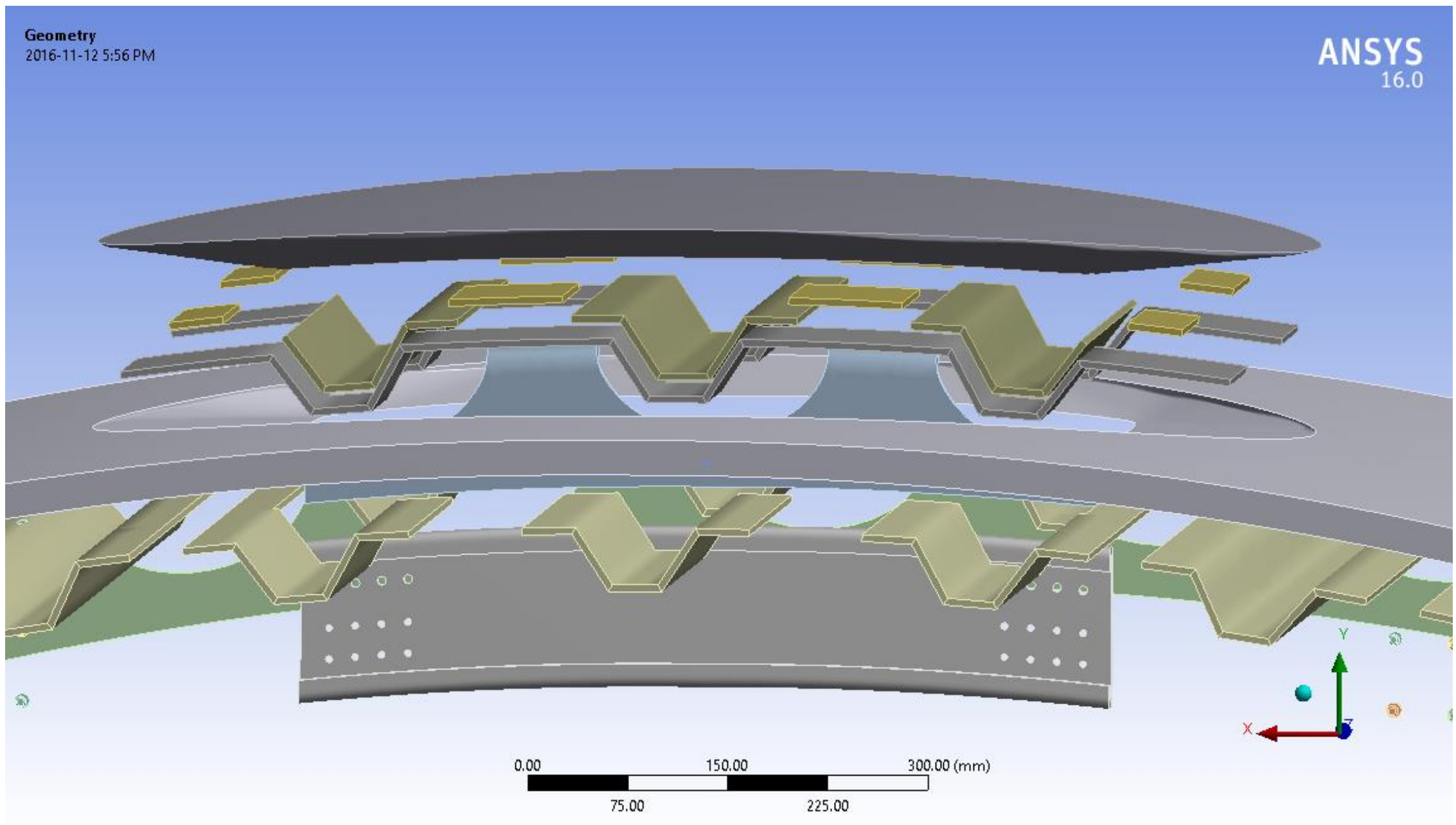



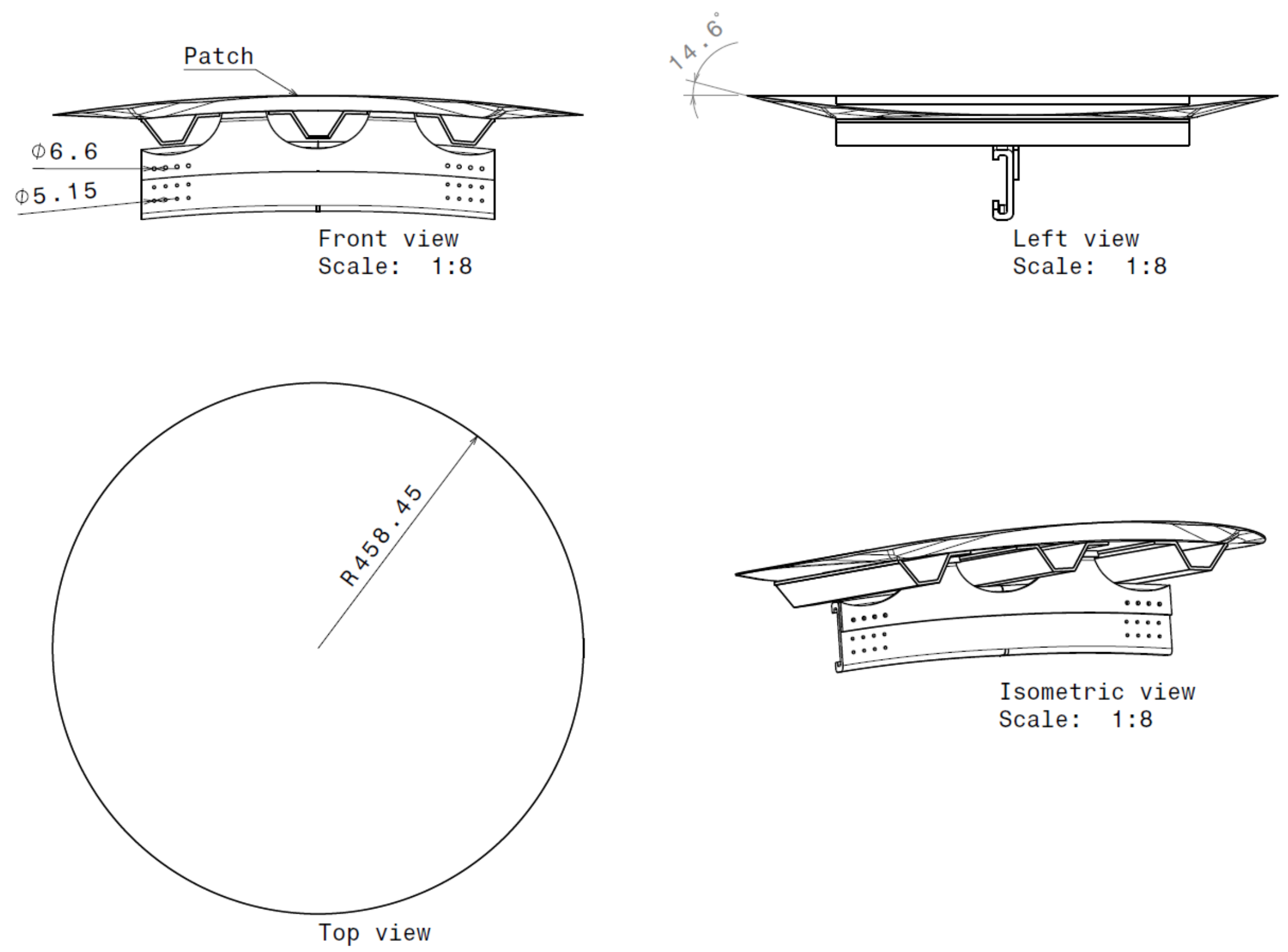

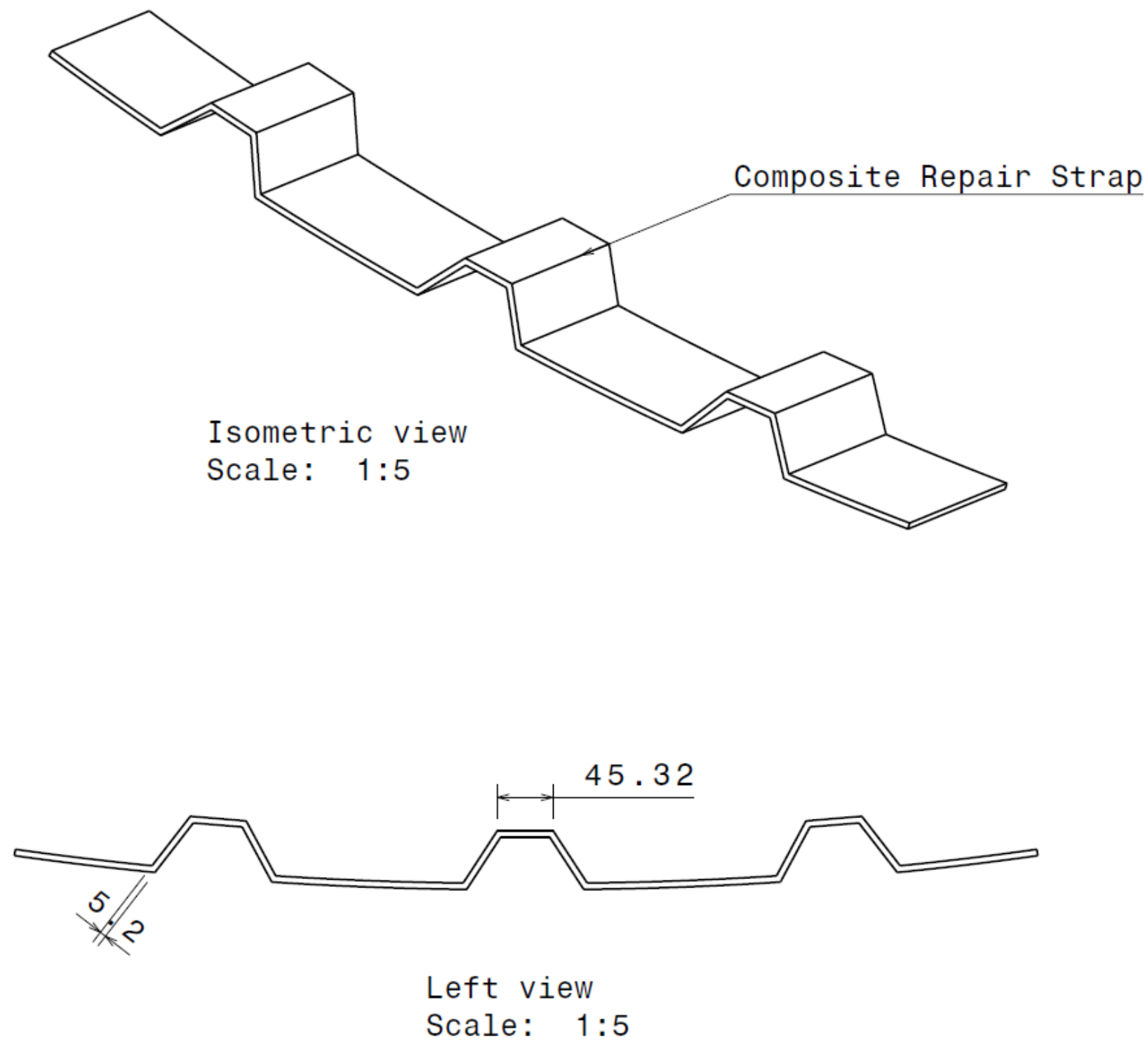


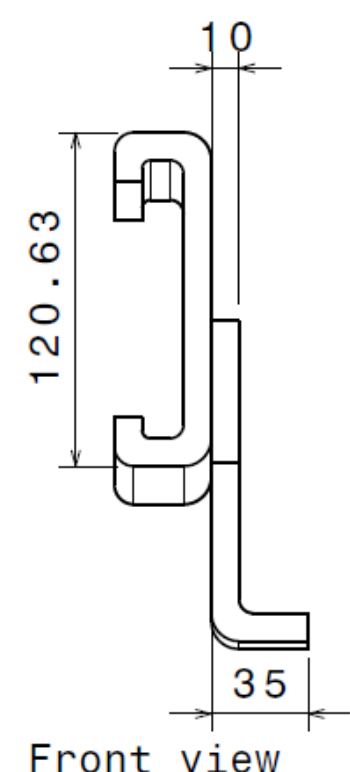

Front view

Scale: 1:3
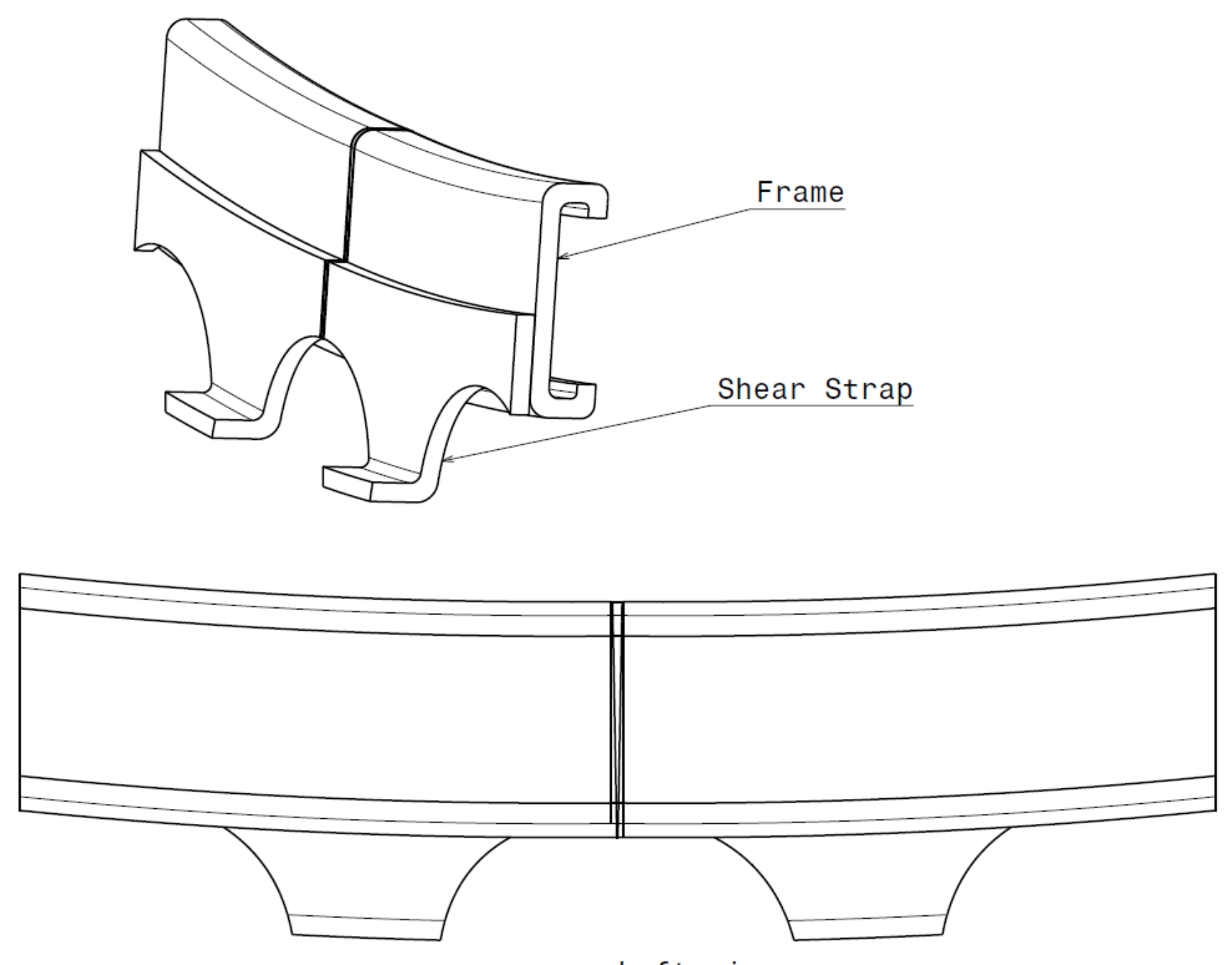

Left view

Scale: 1:3 


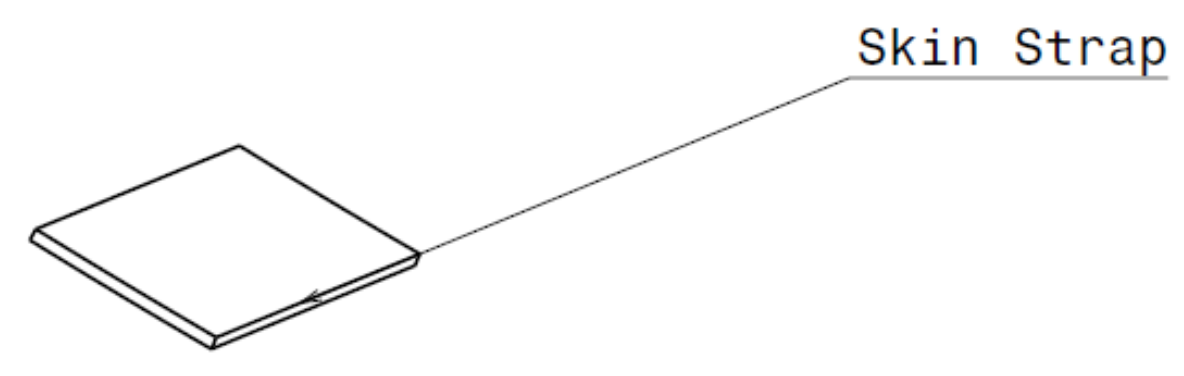

Isometric view

Scale: 1:4
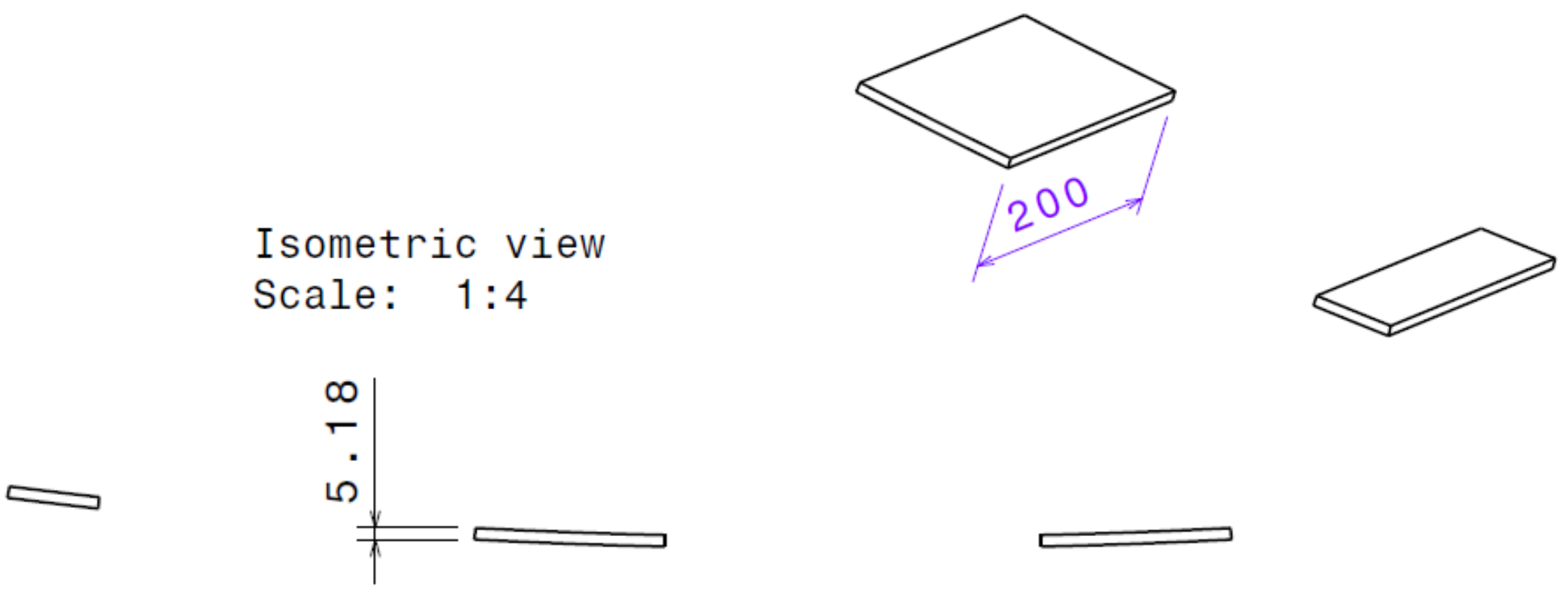

Top view
Scale: $1: 4$ 


\section{$\underline{\text { References }}$}

[1] Conradi K., "Aircraft Accident Report: Report on the serious incident to Boeing B787-8, ET-AOP London Heathrow Airport on 12 July 2013," Hampshire , 2015.

[2] Composite Materials Handbook Vol. 3 Polymer Matrix Composites Materials Usage, Design, and Analysis, 2002.

[3] Irving P. and Soutis C., Polymer Composites in the Aerospace Industry. Cambridge, United Kingdom : Woodhead Publishing, 2015.

[4] Gama B., Mahdi S., Cichanowski C., Yarlagadda S., and Gillespie J., "Static and Dynamic Strength of Scarf-Repaired Thick Section Composite Plates," West Conshohocken, 2004.

[5] Katnam K., Comer D., Silva L., and Young T., "Composite Repair in Wind Turbine Blades: An Overview," The Journal of Adhesion, vol. 91, pp. 113-139, 2015.

[6] Alexander R. (2000, June) EAA The Spirit of Aviation: Repairing Composite Surfaces. [Online]. Retrieved from < http://www.eaa.org/en/eaa/aviation-communities-and-interests/homebuilt-aircraftand-homebuilt-aircraft-kits/resources-for-while-youre-building/building-articles/composite/repairingcomposite-surfaces> [Accessed: October 15, 2016]

[7] "Organizational and Intermediate Maintenance: General Composite Repair NAVAIR 01-1A-21," NATEC, San Diego, CA, Technical Manual 2005.

[8] MAF a Trimis company. (2016, October) Visu-Lok Fasteners. [Online]. Retrieved from $<$ http://www.monogramaerospace.com/products/blind_bolts/visu-lok> [Accessed: October 15, 2016]

[9] MAF Monogram Aerospace Fasteners. [Online]. Retrieved from <http://www.peerlessaerospace.com/Productimages/MG_VISULOK.pdf> [Accessed: October 15, 2016] 
[10] Neubauer M. and Gunther G., "Aging Aircraft Fleets: Structural and Other Subsystem Aspects Aircraft Loads," Sofia , Unclassified document ADP010772 , 2000. [Online]. Retrieved from <http://www.dtic.mil/dtic/tr/fulltext/u2/p010772.pdf> [Accessed: October 15, 2016]

[11] Amq H. N. (2011, April) H.N. AmQ's Blog: Aircraft Load (Part 1). [Online]. Retrieved from <https://hendrynoya.wordpress.com/2011/04/17/aircraft-load-part-i/> [Accessed: October 15, 2016]

[12] Sadraey M., Aircraft Performance.: VDM Publishing, 2009.

[13] Federal Aviation Authority , "Part 25: Airworthiness Standards: Transport Category," Federal Aviation Regulations 1964.

[14] Logan D. L., A First Couse in the Finite Element Method, 5th ed. United States of America : Global Engineering: Christopher M. Shortt, 2012.

[15] Ansys Inc. (2010) SOLID187. [Online]. Retrieved from

<http://inside.mines.edu/ apetrell/ENME442/Documents/SOLID187.pdf> [Accessed: December $19,2016]$

[16] Ansys Inc. 4.174 CONTA174 3-D 8-Node Surface-to-Surface Contact. [Online]. Retrieved from <http://www.ansys.stuba.sk/html/elem_55/chapter4/ES4-174.htm>[Accessed: December 19, 2016]

[17] (2016) Chapter 15: The Patch Test. [Online]. Retrieved from <http://www.colorado.edu/engineering/CAS/courses.d/AFEM.d/AFEM.Ch15.d/AFEM.Ch15.pdf> [Accessed: November 20, 2016] 